\title{
COMPARAÇÃO ENTRE DOIS MÉTODOS ANALÍTICOS PARA DETERMINAÇÃO DA LIGNINA DE ALGUMAS GRAMÍNEAS FORRAGEIRAS'
}

\author{
ROMUALDO SHIGUEO FUKUSHIMA², ARTUR JORDÃO DE MAGALHÃES ROSA ${ }^{3}$, \\ CÉSAR GONÇALVES DE LIMA ${ }^{4}$ e JOSÉ APARECIDO DA CUNHA ${ }^{5}$
}

\begin{abstract}
RESUMO - Foram comparados dois métodos analíticos para a determinação da lignina (lignina em detergente ácido - LDA e lignina permanganato de potássio - LPer) bem como para averiguar a possível relação dos teores desse componente com a digestibilidade da fibra dos seguintes fenos: andropogon (Andropogon gayanus); aveia (Avena sativa); e dois tipos de coast-cross (Cynodon dactylon), um bem fenado e outro de baixa qualidade. Os valores de LDA e LPer foram diferentes $(\mathrm{p} \leq 0,05)$ entre as gramíneas estudadas, com as concentrações de LPer consistentemente mais baixas do que as de LDA. Foram detectadas diferenças $(\mathrm{p} \leq 0,05)$ nos valores de digestibilidade da fibra em detergente neutro (FDN) e da fibra em detergente ácido (FDA), porém, não foi detectada clara relação desses valores com teores de lignina. Os dados sugerem que a concentração de lignina não é o principal fator a explicar um dado valor de digestibilidade.
\end{abstract}

Termos para indexação: digestibilidade, feno, fibra em detergente ácido, fibra em detergente neutro.

\section{COMPARISON BETWEEN TWO ANALYTICAL METHODS FOR DETERMINING LIGNIN CONCENTRATION OF SOME GRASS FORAGES}

\begin{abstract}
This work was carried out aiming to compare lignin concentration of some grass forages through two analytical methods (acid detergent lignin - ADL and permanganate lignin - PerL) as well to verify a possible relationship of lignin concentration with fiber digestion of the following grass hays: andropogon (Andropogon gayanus); oats (Avena sativa); a good quality and another of poor quality coast-cross (Cynodon dactylon). Acid detergent and permanganate lignin values were different $(\mathrm{p} \leq 0.05)$ among the hays, however PerL concentrations were consistently lower than ADL values. There were differences $(\mathrm{p} \leq 0.05)$ among the digestibility of neutral and acid detergent fiber fractions, however a clear relationship between these values with lignin concentration could not be assessed. The data suggested that lignin concentration, taken individually, is not the only factor to explain a given value of digestibility.
\end{abstract}

Index terms: digestibility, hay, neutral detergent fiber, acid detergent fiber.

\section{INTRODUÇÃO}

A lignina, um polímero não-carboidrato, composto de monômeros fenólicos (do tipo fenilpropano),

\footnotetext{
${ }^{1}$ Aceito para publicação em 14 de agosto de 1998.

Projeto financiado pelo CNPq.

${ }^{2}$ Méd. Vet., Prof. Associado, Faculdade de Zootecnia e Engenharia de Alimentos, Universidade de São Paulo (FZEA-USP), Campus de Pirassununga, CEP 13630-000 Pirassununga, SP. E-mail: rsfukush@usp.br

${ }^{3}$ Zoot., M.Sc., FZEA-USP. Bolsista da FAPESP

${ }^{4}$ Estatístico, Dr., Prof. Assistente, FZEA-USP.

${ }^{5}$ Biomédico, M.Sc., FZEA-USP.
}

reconhecidamente é um dos principais componentes responsáveis pela queda da digestibilidade dos nutrientes das plantas forrageiras (Van Soest, 1963; Ford, 1978; Jung \& Vogel, 1986), e tem sido justamente por esta razão útil na estimativa da extensão da digestão da fibra (Barton II \& Akin, 1977). A lignina, por mecanismos ainda discutidos (Dehority \& Johnson, 1961; Hartley \& Jones, 1977; Morrison, 1983), inibe consideravelmente a digestibilidade da matéria seca.

As análises laboratoriais de plantas forrageiras são necessárias para estimar a qualidade nutritiva e, conseqüentemente, predizer a extensão da degradação biológica (Van Soest \& Robertson, 1980). No 
entanto, qualquer estimador de digestibilidade precisa ser determinado quimicamente com níveis aceitáveis de precisão e acurácia (Faichney, 1975). Dois métodos analíticos para mensuração do teor de lignina em plantas forrageiras são amplamente empregados: a lignina em detergente ácido (LDA) e a lignina permanganato de potássio (LPer). Na técnica da LDA, a amostra é previamente tratada com solução de detergente ácido, resultando na fibra em detergente ácido (FDA), que após é submetida à digestão com solução concentrada de ácido sulfúrico a 72\% (Van Soest, 1963). No entanto, este método apresenta alguns inconvenientes, tais como: mensurar cutina como sendo lignina (Goering \& Van Soest, 1970); amostras de LDA podem estar contaminadas com artefatos de Maillard (Johnson, 1963); parte da lignina é potencialmente solúvel na solução de ácido sulfúrico a 72\% (Iiyama \& Wallis, 1990; Hatfield et al., 1994). Por sua vez, a aceitação do método LPer vem aumentando gradativamente. Entretanto, esta técnica analítica tem também sido alvo de algumas críticas, como: não tratar uniformemente as partículas de tamanhos diversos (Goering \& Van Soest, 1970); a celulose pode ser parcialmente solubilizada se excessiva quantidade da solução de permanganato for empregada, particularmente em gramíneas imaturas (Van Soest \& Wine, 1968); a hemicelulose e certos tecidos do mesófilo da fração fibra em detergente neutro de festuca são removidos pelo tratamento oxidativo (Barton II \& Akin, 1977). Usualmente, o método LPer tem produzido resultados de maior magnitude quando comparada à técnica da LDA (Rebolé et al., 1989). Van Soest \& Wine (1968) levantaram a hipótese de que os valores observados com o método LPer poderiam estar mais próximos da realidade.

A concentração de lignina nas plantas forrageiras tem sido constantemente responsabilizada como um dos fatores limitantes da digestibilidade da planta. Embora as correlações entre teor de lignina e digestibilidade sugiram esta associação, não são necessariamente provas que a lignina seja realmente a principal responsável pela menor digestibilidade da matéria seca (Jung, 1989). Entretanto, quando se trata de relacionar concentração de lignina com a digestibilidade das frações fibrosas, que são os sítios onde a lignina exerce o seu efeito deletério na digestão, os resultados poderão ser melhor evidenciados. Jung \& Vogel (1986) sugeriram que a lignina inibe primordialmente a digestão da parede celular do que a digestão da totalidade da matéria seca.

Portanto, os objetivos da presente pesquisa foram obter concentrações de lignina de algumas gramíneas mediante dois métodos analíticos e comparar os dados, por meio de análises de regressão, com os valores de digestibilidade in vivo das frações fibrosas dessas gramíneas.

\section{MATERIAL E MÉTODOS}

\section{Animais e dietas}

A parte experimental foi conduzida nas dependências da Faculdade de Zootecnia e Engenharia de Alimentos da Universidade de São Paulo, situada no Campus de Pirassununga, SP, nos meses de novembro e dezembro de 1992. Foram utilizados 12 carneiros, castrados, da raça Ideal, peso médio de $46,6 \mathrm{~kg}$, alojados em gaiolas metabólicas e obtendo-se as fezes por método de coleta total, com o emprego de bolsas coletoras. O delineamento estatístico foi o completamente casualizado, sendo três animais distribuídos ao acaso para cada um dos quatro tratamentos (oito graus de liberdade para o resíduo); as médias foram comparadas pelo teste de Tukey a $5 \%$ de probabilidade, após determinar-se a significância do valor de "F" pelo teste de ANOVA (Snedecor \& Cochran, 1980).

As dietas que compuseram os quatro tratamentos foram baseadas em $70 \%$ de volumoso e $30 \%$ de concentrado. Os volumosos foram os fenos das seguintes gramíneas: A) andropogon (Andropogon gayanus); B) aveia (Avena sativa); C) coast-cross (Cynodon dactylon) bem fenado coast-cross I; e D) coast-cross de baixa qualidade - coastcross II. A mistura concentrada foi composta de milho moído, farelo de algodão, casca de algodão, calcário, fosfato bicálcico, sal e premix vitamínico-mineral. A composição dos ingredientes das rações é mostrada na Tabela 1, e a proporção dos ingredientes, na Tabela 2.

No tratamento B, a participação do feno de aveia como volumoso teve que ser parcialmente limitada e complementada com casca de algodão, pelo alto teor de proteína bruta e valor relativamente baixo de FDN.

O período de adaptação teve a duração de 17 dias enquanto o de coleta de fezes foi de cinco dias. A oferta de matéria seca foi de $2,5 \%$ do peso vivo dos animais no período de adaptação, sendo metade de manhã e a outra metade no final da tarde; e dois dias antes do período de coleta, a alimentação foi restringida para $80 \%$ do consumo. Com relação às sobras, adotou-se como critério que, 
sendo inferiores a $100 \mathrm{~g}$, o material seria remontado à alimentação seguinte; caso contrário, seria coletado e armazenado para posterior análise bromatológica. As fezes foram coletadas e pesadas de manhã, sendo guardadas $50 \%$ de cada animal para cada dia; após o período de coleta, as fezes de cada animal foram devidamente homogeneizadas e uma alíquota de $200 \mathrm{~g}$ congelada para posterior análise bromatológica.

\section{Análises laboratoriais}

As análises bromatológicas da matéria seca, proteína bruta e extrato etéreo foram executadas de acordo com as normas da Association of Official Analytical Chemists (1970). Os teores de FDN, de FDA, de LDA e de LPer

TABELA 1. Composição de proteína bruta e fibra em detergente neutro dos ingredientes das rações experimentais ${ }^{1}$.

\begin{tabular}{lrrrr}
\hline Ingrediente & $\mathrm{PB}$ & $\mathrm{FDN}$ & $\mathrm{Ca}$ & $\mathrm{P}$ \\
\hline Feno andropogon & 7,2 & 67,1 & 0,5 & 0,2 \\
Feno aveia & 12,9 & 57,0 & 0,4 & 0,2 \\
Feno coast-cross I & 10,8 & 70,5 & 0,4 & 0,2 \\
Feno coast-cross II & 8,2 & 69,4 & 0,3 & 0,2 \\
Milho moído & 9,5 & 3,4 & 0,1 & 0,1 \\
Farelo algodão & 30,9 & 30,5 & 0,2 & 0,6 \\
Casca algodão & 4,3 & 90,0 & 0,2 & 0,1 \\
Calcário & - & - & 38,0 & - \\
Fosfato bicálcico & - & - & 23,0 & 18,0 \\
\hline
\end{tabular}

${ }^{1}$ Dados expressos em porcentagens de matéria seca; $\mathrm{PB}$ - proteína bruta; FDN - fibra em detergente neutro; $\mathrm{Ca}$ - cálcio; $\mathrm{P}$ - fósforo.

TABELA 2. Proporção dos ingredientes nas dietas experimentais nos quatro tratamentos ${ }^{1}$.

\begin{tabular}{lcccc}
\hline Material & Trat. A & Trat. B & Trat. C & Trat. D \\
\hline Feno andropogon & 69,0 & - & - & - \\
Feno aveia & - & 39,0 & - & - \\
Feno coast-cross I & - & - & 69,0 & - \\
Feno coast-cross II & - & - & - & 69,0 \\
Milho moído & 10,2 & 17,6 & 21,6 & 13,1 \\
Farelo algodão & 19,4 & 11,6 & 7,8 & 16,2 \\
Casca algodão & - & 30,0 & - & - \\
Calcário & - & - & 0,1 & 0,4 \\
Fosfato bicálcico & 0,4 & 0,8 & 0,5 & 0,3 \\
Sal + Premix & 1,0 & 1,0 & 1,0 & 1,0 \\
\hline
\end{tabular}

${ }_{1}$ Dados expressos em porcentagens de matéria seca; as dietas foram balanceadas para conterem $12 \%$ de PB e aproximadamente $53 \%$ de FDN foram determinados conforme Goering \& Van Soest (1970).

\section{RESULTADOS E DISCUSSÃO}

A composição bromatológica das quatro rações experimentais está apresentada na Tabela 3. Nos dois métodos, os valores de LDA e LPer foram diferentes $(p \leq 0,05)$ entre os tratamentos (Tabela 3$)$, mas ambos revelaram tendência de os teores de lignina seguirem para a mesma direção, isto é, o tratamento contendo aveia foi o que apresentou maior teor de lignina, seguido dos tratamentos coast-cross de baixa qualidade, andropogon e coast-cross de boa qualidade. Diferentemente do que usualmente tem sido reportado na literatura (Van Soest \& Wine, 1968; Rebolé et al., 1989), os teores de LPer foram ligeiramente inferiores aos valores de LDA, e à exceção do tratamento coast-cross I, não houve diferença estatística entre os tratamentos $(\mathrm{p}>0,05)$. No presente estudo, as amostras experimentais para as análises laboratoriais foram as dietas completas, ou seja, em todas elas houve significativa participação de alimentos concentrados, e também o tratamento aveia, contendo alta porcentagem de casca de algodão. Alimentos concentrados, principalmente aqueles contendo cascas, são ricos em cutina (Van Soest, 1994). Valores de LDA da pesquisa em pauta, podem estar artificialmente inflacionados, pois a cutina é mensurada na fração LDA (Fukushima et al., 1991; Fukushima \& Dehority, 1995). Muntifering (1982) observou valor numérico mais elevado de LDA em relação à LPer no tratamento contendo casca de al-

TABELA 3. Composição bromatológica das dietas experimentais $(\%)^{1}$.

\begin{tabular}{lcccccc}
\hline Tratamento & PB & EE & FDN & FDA & LDA & LPer \\
\hline Andropogon & 11,0 & 2,1 & $53,3 \mathrm{~b}$ & $29,7 \mathrm{~b}$ & $12,1 \mathrm{c}$ & $11,7 \mathrm{c}$ \\
Aveia & 10,2 & 2,1 & $54,5 \mathrm{~b}$ & $32,6 \mathrm{a}$ & $15,8 \mathrm{a}$ & $14,3 \mathrm{a}$ \\
Coast-cross I & 10,5 & 2,7 & $57,3 \mathrm{a}$ & $28,2 \mathrm{c}$ & $12,6 \mathrm{c}$ & $10,6 \mathrm{~d}$ \\
Coast-cross II & 10,1 & 2,4 & $56,6 \mathrm{a}$ & $28,8 \mathrm{c}$ & $13,7 \mathrm{~b}$ & $12,6 \mathrm{~b}$ \\
\hline 1 & $\begin{array}{l}\text { Médias na mesma coluna seguidas por letras diversas, diferem entre si } \\
\text { (p < 0,05); PB - proteína bruta; EE - extrato etéreo; FDN - fibra em }\end{array}$ \\
$\begin{array}{l}\text { detergente neutro; FDA - fibra em detergente ácido; LDA - lignina em } \\
\text { detergente ácido; LPer - lignina permanganato de potássio. }\end{array}$
\end{tabular}


godão e creditou tal observação às presenças de cutina e gossipol.

A digestibilidade da MS não diferiu entre os tratamentos $(p>0,05)$. No entanto, observaram-se diferenças $(p \leq 0,05)$ nas digestibilidades das frações fibrosas FDN e FDA (Tabela 4). A tentativa de relacionar teores de lignina apenas com a digestibilidade da MS pode ser equivocada, uma vez que a principal ação da lignina é sobre a parede celular e não sobre o conteúdo celular (Van Soest, 1994). As correlações $\left(\mathrm{r}^{2}\right)$ entre os métodos LDA e LPer com a digestibilidade da MS não foram significativas ( $p>0,05)$, apresentando valores de 0,36 e 0,38 , respectivamente. Van Soest (1967) já havia indicado que o conteúdo celular não é lignificado, podendo em certos casos, como nas leguminosas, exceder em $60 \%$ o total da matéria seca.

Experimentos de digestibilidade in vivo, pela sua própria natureza, limitam o número de observações. Obviamente, um número maior de forrageiras testadas permitiria melhor definição na relação lignina:digestibilidade. Enquanto a digestibilidade da fração FDN do coast-cross de boa qualidade foi superior $(\mathrm{p} \leq 0,05)$ à do FDN de andropogon, não ocorreram diferenças $(\mathrm{p}>0,05)$ quanto à LDA entre ambas as gramíneas. Apesar de a concentração de lignina ser o principal fator a interferir na digestibilidade de plantas forrageiras, outros devem ser considerados, tais como grau de cristalinização da celulose, teor de sílica, distribuição da lignina sobre a parede celular (Van Soest, 1994). Também, embora exista forte correlação entre quantidade de lignina e digestibilidade, é bem possível que a composição química da lignina seja um fator mais im-

TABELA 4. Valores de digestibilidade aparente em carneiros $(\%)^{1}$.

\begin{tabular}{llll}
\hline Tratamento & MS & FDN & FDA \\
\hline Andropogon & $58,9 \mathrm{a}$ & $50,0 \mathrm{~b}$ & $40,7 \mathrm{ab}$ \\
Aveia & $60,8 \mathrm{a}$ & $51,5 \mathrm{ab}$ & $37,8 \mathrm{~b}$ \\
Coast-cross I & $59,8 \mathrm{a}$ & $54,9 \mathrm{a}$ & $49,4 \mathrm{a}$ \\
Coast-cross II & $59,6 \mathrm{a}$ & $52,2 \mathrm{ab}$ & $45,1 \mathrm{a}$ \\
\hline
\end{tabular}

${ }^{1}$ Médias na mesma coluna seguidas por letras diversas, diferem entre si ( $\mathrm{p}<0,05)$; MS - matéria seca; FDN - fibra em detergente neutro; FDA - fibra em detergente ácido. portante do que sua concentração na determinação da digestibilidade da planta (Jung, 1989; Fukushima, 1996). Outro aspecto a ser levado em conta é a correlação observada entre teor de lignina e digestibilidade das frações FDN e FDA; correlações mais elevadas foram verificadas entre conteúdo de lignina e digestibilidade da fração FDA do que a fração FDN (Van Soest, 1994); no presente experimento não foram significativas $(p>0,05)$ as correlações entre teores de lignina obtidos pelos dois métodos com a digestibilidade da FDN; entretanto, houve significância estatística ( $\mathrm{p} \leq 0,05)$ entre os métodos LDA e LPer com os valores de digestibilidade da FDA $\left(r^{2}=-0,64\right.$ e $r^{2}=-0,75$, respectivamente). Tal observação vai de encontro à constatação de que teores de lignina (tanto LDA como LPer) puderam explicar a menor digestibilidade $(\mathrm{p} \leq 0,05)$ da preparação FDA do tratamento aveia em relação à digestibilidade da FDA dos fenos de coast-cross. As Figs. 1 e 2 mostram as relações existentes entre os teores de lignina e a variação da digestibilidade da MS e das frações fibrosas FDN e FDA.

É possível que a casca de algodão possa ter tido alguma interferência nos resultados. Entretanto, é de se esperar que a presença da casca de algodão no tratamento aveia tenha interferido não apenas na mensuração da concentração de lignina como também nos valores obtidos nas digestibilidades das preparações FDN e FDA. Além disso, o tratamento aveia foi o que apresentou os maiores teores

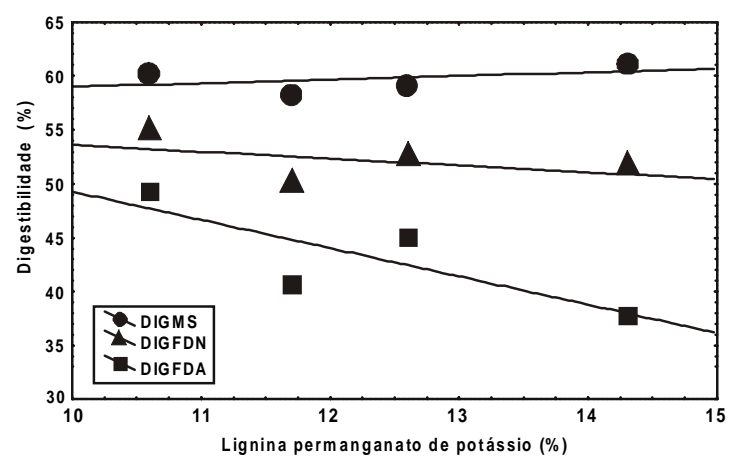

FIG. 1. Relação entre os teores de lignina permanganato de potássio e os valores médios de digestibilidade das frações fibrosas (FDN e FDA) e da matéria seca (MS). 


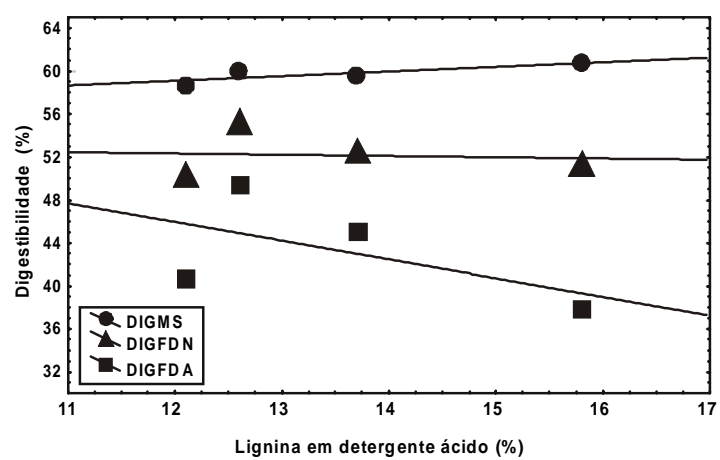

FIG. 2. Relação entre os teores de lignina em detergente ácido e os valores médios de digestibilidade das frações fibrosas (FDN e FDA) e da matéria seca (MS).

( $\mathrm{p} \leq 0,05)$ de LDA e de LPer, mas também, paralelamente, o menor valor de digestibilidade $(\mathrm{p} \leq 0,05)$ da fração FDA ao lado do tratamento andropogon.

\section{CONCLUSÕES}

1. Os métodos LDA e LPer medem diferentemente os teores de lignina nas plantas forrageiras.

2. Enquanto os fenos apresentam valores similares de digestibilidade da matéria seca, as frações fibrosas FDN e FDA apresentam valores desiguais.

\section{REFERÊNCIAS}

ASSOCIATION OF OFFICIAL ANALYTICAL CHEMISTS. Official methods of analysis. 11.ed. Washington, DC, 1970. 1015p.

BARTON II, F.E.; AKIN, D.E. Digestibility of delignified forage cell walls. Journal of Agricultural and Food Chemistry, v.25, p.1299-1303, 1977.

DEHORITY, B.A.; JOHNSON, R.R. Effect of particle size upon the in vitro cellulose digestibility of forages by rumen bacteria. Journal of Dairy Science, v.44, p.2242-2249, 1961.

FAICHNEY, G.J. The use of markers to partition digestion within the gastrointestinal tract of ruminants. In: McDONALD, I.W.; WARNER, A.C.I. (Eds.). Digestion and metabolism in the ruminant. Armidale: The Univ. of New England Publ. Unit., 1975. 602p.
FORD, C.W. Effect of partial delignification on the in vitro digestibility of cell wall polysaccharides in Digitaria decumbens (Pangola grass). Australian Journal of Agricultural Research, v.29, p.11571166, 1978.

FUKUSHIMA, R.S. Extração da lignina através do brometo de acetila e seu emprego objetivando avaliação quantitativa da lignina de plantas. In: REUNIÃO ANUAL DA SOCIEDADE BRASILEIRA DE ZOOTECNIA, 33., 1996, Fortaleza. Anais... Fortaleza: SBZ, 1996, v.3, p.318-320.

FUKUSHIMA, R.S.; DEHORITY, B.A. Modificação do método colorimétrico "lignina solúvel em brometo de acetila" na estimativa quantitativa da lignina. Revista da Sociedade Brasileira Zootecnia, v.24, p.192-203, 1995.

FUKUSHIMA, R.S.; DEHORITY, B.A.; LOERCH, S.C. Modification of a colorimetric analysis for lignin and its use in studying the inhibitory effect of lignin on forage digestion by rumen microorganisms. Journal of Animal Science, v.69, p.295-304, 1991.

GOERING, H.K.; VAN SOEST, P.J. Forage fiber analysis (Apparatus, reagents, procedures and some applications). Washington, DC: USDA, 1970. (Agricultural Handbook, 379).

HARTLEY, R.D.; JONES, E.C. Phenolic components and degradability of cell walls of grass and legume species. Phytochemistry, v.16, p.1531-1534, 1977.

HATFIELD, R.D.; JUNG, H.G.; RALPH, J.; BUXTON, D.R.; WEIMER, P.J. A comparison of the insoluble residues produced by the Klason lignin and acid detergent lignin procedures. Journal of the Science of Food and Agriculture, v.65, p.51-58, 1994.

IIYAMA, K.I.; WALLIS, A.F.A. Determination of lignin in herbaceous plants by an improved acetyl bromide procedure. Journal of the Science of Food and Agriculture, v.51, p.145-161, 1990.

JOHNSON, R.R. Symposium on microbial digestion in ruminants: "in vitro" rumen fermentation techniques. Journal of Animal Science, v.22, p.792-800, 1963.

JUNG, H.G. Forage lignins and their effects on fiber digestibility. Agronomy Journal, v.81, p.33-38, 1989.

JUNG, H.G.; VOGEL, K.P. Influence of lignin on digestibility of forage cell wall material. Journal of Animal Science, v.62, p.1703-1712, 1986.

MORRISON, I.M. The effect of physical and chemical treatments on the degradation of wheat and barley 
straws by rumen liquor-pepsin and pepsin-cellulose systems. Journal of the Science of Food and Agriculture, v.34, p.1323-1329, 1983.

MUNTIFERING, R.B. Evaluation of various lignin assays for determining ruminal digestion of roughages by lambs. Journal of Animal Science, v.55, p.432-438, 1982.

REBOLÉ, A.; ALVIRA, P.; GONZÁLEZ, G. Variation of chemical composition data of agricultural and forest fibrous by-products as determined by the two detergent systems of analysis. Journal of the Science of Food and Agriculture, v.48, p.141-153, 1989.

SNEDECOR, G.W.; COCHRAN, W.G. Statistical methods. 7.ed. Ames: The Iowa State Univ. Press, 1980. $507 \mathrm{p}$

VAN SOEST, P.J. Development of a comprehensive system of feed analysis and its application to forages. Journal of Animal Science, v.26, p.119-128, 1967.
VAN SOEST, P.J. Nutritional ecology of the ruminant 2.ed. Ithaca, NY: Cornell Univ. Press, 1994.

VAN SOEST, P.J. Use of detergents in the analysis of fibrous foods. II. A rapid method for the determination of fibre and lignin. Journal of the Association of the Official Analytical Chemists, v.46, p.829-835, 1963.

VAN SOEST, P.J.; ROBERTSON, J.B. Systems of analysis for evaluating fibrous feeds. In: PIDGEN, W.J.; BALCH, C.C.; GRAHAM, M. (Eds.). Standardization of analytical methodology for feeds. Ottawa: International Development Research Centre, 1980. p.49-60.

VAN SOEST, P.J.; WINE, R.H. The determination of lignin and cellulose in acid-detergent fibre with permanganate. Journal of the Association of Official Analytical Chemists, v.51, p.780-785, 1968. 